\title{
Rethinking engagement: Exploring women's technology use during the perinatal period through a Kaupapa Māori consistent approach
}

\author{
Norina Gasteiger ${ }^{A, B} B H S C$ (Hons), BA - Anneka Anderson ${ }^{C}$ PhD, MA, BA - Karen Day FACHI, PhD,
} MA, RM, RN

${ }^{\mathrm{A}}$ Corresponding Author: n.gasteiger@ auckland.ac.nz

${ }^{\text {B }}$ School of Population Health, The University of Auckland

${ }^{\mathrm{C}}$ Te Kupenga

Hauora Māori,

The University of Auckland

\begin{abstract}
Background: Barriers to accessing perinatal health services in New Zealand remain a significant problem, especially for Māori and rural populations. Information technologies and telehealth can facilitate the distribution of health-related information and promote provider engagement during the perinatal period.
\end{abstract}

Aim: This study explored the perceptions and use of technologies by women and their partners who were pregnant or new mothers/caregivers and who utilised Kaupapa Māori perinatal health services.

Method: A Kaupapa Māori consistent methodology was applied. An equal explanatory sampling approach was used for recruitment. Conversational interviews were conducted with a total of nine Northland-residing participants of an antenatal programme. Data were analysed thematically.

Findings: Four overarching themes emerged from the interview narratives: communication, information, facilitators and barriers. Participants used a range of online tools to access diverse healthrelated topics and executed autonomous control over the information gained. The credibility and reputability of sources as well as knowledge sharing were valued. Similar technologies were used to communicate with perinatal healthcare providers, including lead maternity carers, and to make in-person appointments. Barriers were related to the technology itself or the experience of using it, whilst ease of access and emotional elements facilitated engagement. Participants were generally satisfied with the technologies.

Conclusion: Technology can play an important role in health literacy and minimising barriers to perinatal healthcare, by facilitating the distribution of information and promoting provider engagement. As the research indicated that online tools and services available in Northland are generally adequate for the population served, perinatal healthcare providers should leverage these to further promote engagement with service users. It is crucial that Māori health values such as whānau (extended family structures) and kanohi ki te kanohi (face-to-face interactions) are incorporated for successful perinatal healthcare delivery via telehealth.

Keywords: Māori, perinatal, telehealth, pregnancy, women, Kaupapa Māori

\section{INTRODUCTION}

The growth of internet connectivity and mobile phone use in New Zealand has led to an increase in social media and mobile application (app) use. A recent report identified that the smartphone is the nation's most popular device, with an increase of ownership from $48 \%$ in 2013 to $70 \%$ in 2015 (Research New Zealand, 2015). Additionally, $91 \%$ of smartphone owners reported using their mobile device daily and half report using it more than they did the year before, most of whom (86\%) use it to connect to the internet. Furthermore, $87 \%$ of those aged $18-34$ years, $75 \%$ of those aged $34-54$ years and $58 \%$ of those aged 55 years or older use social media apps (Research New Zealand, 2015). These rates are predicted to continue to rise with increasing access to the internet. For example, an additional 134,115 people who identified as Māori gained access to the internet between 2006 and 2013 (Statistics New Zealand, 2013). However, the ability to access information online is accompanied by a greater likelihood of being exposed to misleading information. For health-related advice, such as during the perinatal period, this can be harmful for both woman and baby.

Within healthcare, the use of information and communication technologies for education, research, administration and treatment purposes is known as "telehealth" (Wootton \& Bonnardot, 2015). Telehealth encompasses a range of digital information technologies, including social media, video-conferencing, blogging and the use of mobile phones and other devices. Benefits of technology use in perinatal healthcare could include convenience, minimised geographical barriers, improved health literacy, cost-effectiveness for providers and service users and increased confidence through emotional and practical support, and timely aid (Entsieh, Emmelin, \& Pettersson, 2015; Friesen, Hormuth, Petersen, \& Babbitt, 2015; Hod \& Kerner, 2003; Jareethum et al., 
2008; Lindberg, Axelsson, \& Öhrling, 2009; Lund et al., 2014). Technology use can provide opportunities for increased access to perinatal healthcare.

Access to quality healthcare during the perinatal period is important and can affect both the mother's and the baby's health outcomes (World Health Organization, 2017). The perinatal period starts at 154 days of gestation and continues until seven days after birth; so related healthcare is provided throughout pregnancy, birth and postpartum (World Health Organization, 2017). Although this care is publicly funded nationally and therefore at no cost to the consumer at the point of care, many Māori women experience other access barriers. For example, Corbett, Chelimo and Okesene-Gafa (2014) identified that the odds of late booking for antenatal care are six times more likely amongst Māori women compared to New Zealand European and other ethnic groups. Makowharemahihi et al. (2014) reported that the young Māori women who participated in their research found that a lack of adequate information on navigating perinatal pathways to discover their choices for primary care providers and nominating a lead maternity carer (LMC) delayed their access to antenatal care. Such barriers can result in unequal health outcomes between those who can easily navigate the pathways and those who struggle to.

Health inequities are also exacerbated by Eurocentric health systems that often fail to incorporate Māori values, practices and concepts of health (Reid \& Robson, 2007). Valued concepts of health for many Māori include whānau (extended family structures) and holistic and traditional practices such as herbal remedies and massage (Cram, Smith, \& Johnstone, 2003; Jones, 2000). The collectivist whānau ora (healthy families) approach includes immediate family, extended family structures and the wider community, whose interconnectedness facilitates wellbeing longevity through future generations and also provides reciprocal support and access to resources (Cram et al., 2003; Durie, 2006; Jones, 2000). Wellbeing is understood to exceed physical health and incorporates a harmonious unity of physical, spiritual and mental health (Cram et al., 2003; Durie, 2006; Jones, 2000). Including these concepts of health in perinatal healthcare practice is important in reducing inequitable health outcomes for Māori.

Inequities are also evident, with Māori being over-represented in the group that suffers stillbirth, neonatal and maternal mortalities, and with Māori women being almost three times as likely as nonMāori to die from suicide (Perinatal and Maternal Mortality Review Committee, 2017). Likewise, more Māori women, when compared with non-Māori women, report barriers to breastfeeding, including a lack of professional support, culturally irrelevant information, feeling pressured by health providers, conflicting advice, and cultural insensitivity (Glover, Manaena-Biddle, \& Waldon, 2007; Glover, Waldon, Manaena-Biddle, Holdaway, \& Cunningham, 2009). Respect for the woman's culture, values, beliefs and background was also found to influence her choice of LMC (Ministry of Health, 2015). These disparities and experiences demonstrate the need for partnership with Māori communities and advocacy of Māori-led research within health contexts to identify interventions that address barriers to perinatal care and promote the longevity of tanngata whenua. One such area is the use of technologies, to deliver appropriate health-related information and to facilitate provider engagement during the perinatal period.

The aim of our study was therefore to explore the perceptions and use of technologies by women who were pregnant or new mothers/ caregivers, and their partners, who utilised Kaupapa Māori perinatal health services (services based on Māori philosophies, values and practices of pregnancy and birthing).

\section{METHODS}

The study applied a qualitative Kaupapa Māori consistent and interpretive approach. The University of Auckland Human Participants Ethics Committee approved the study in 2017 (Reference 019135), which included the participating district health board's (DHB's) locality approval (Reference 2017-11).

\section{Kaupapa Māori consistent research}

Kaupapa Māori research (KMR) provides a critical analysis of power relationships, centralises Māori paradigms and aims to improve the wellbeing of Māori through collaborative research with Māori communities (Malpas et al., 2017; Mane, 2009; Pipi et al., 2004). A Kaupapa Māori consistent methodology was employed, as two of the three researchers were non-Māori (Malpas et al., 2017). Although this research approach aligns with the principles of pure KMR by centralising Māori paradigms, language and values, negotiations must be undertaken to ensure that ownership and benefits are maintained for Māori (Malpas et al., 2017; Smith, 1992). Consultation was undertaken with Māori researchers and the DHB to collaboratively design the research. The project was also reviewed and supported by the Tommaiora Māori research unit at The University of Auckland, and followed their policies for culturally safe research practices (Tōmaiora, 2015).

\section{Data collection}

Conversational interviews were conducted with a total of nine participants in a small, rural Northland town. These were undertaken in groups of two or three participants. Conversational interviews in pairs and a triad allowed for the interviews to resemble an informal kōrero (conversation) that reduced ambiguity and increased opportunities for clarification (Eggleton, Kearns, \& Neuwelt, 2017). The inclusion criteria for participants were: (1) being pregnant, identifying as new mothers/caregivers, or their partners, (2) residing in Northland and (3) engaging with Kaupapa Māori perinatal services. An equal explanatory sampling model was applied, meaning that at least half of the participants self-identified as Māori (Te Rōpū Rangahau Hauora a Eru Pōmare, 2015). This aligns with KMR by ensuring that the research captures Māori perspectives, voices and experiences, targets inequities experienced by Māori and is as effective at promoting health outcomes for Māori as it is for non-Māori (Te Rōpū Rangahau Hauora a Eru Pōmare, 2015).

Interviews were conducted during a two-day Kaupapa Māori antenatal programme that was free to attend. Transport was also organised from the wider area. The programme offered a holistic alternative to western biomedical practices by teaching attendees how to incorporate Māori philosophies and practices relating to perinatal health throughout this period. Sessions focused on pregnancy, birth, labour, breastfeeding and car-seat safety, but also included dental health, nutrition and maternal wellbeing.

A kaimahi (Māori health worker) who had established relationships within the community helped to organise the interviews by liaising between the researcher and the attendees and assisted with maintaining Māori authority and guidance of the research (Pipi et al., 2004). The kaimahi outlined the project, introduced the researcher, invited participants to be interviewed and ensured there was a private and quiet room in which to conduct the interviews. Interested participants approached the researcher who set up a time for the interview. Information sheets were provided to all participants and signed consent forms were gathered before the interviews commenced. The interviews were semi-structured, audio-recorded and lasted around 30 minutes. Interactions with 
participants respected manaakitanga (hospitality/respect) through koha (gifts/acknowledgements), food and prayer (Jones, Crengle, \& McCreanor, 2006; Mead, 2003). To protect the confidentiality and anonymity of the participants, the name and location of the antenatal programme have been removed from this report and all participants were assigned pseudonyms.

The interview questions were written on paper and given to participants to ask one another (Table 1). This practice helped shift the power dynamic from the researcher to the participants, thus shifting control to the community, as consistent with KMR practices (Mead, 2003).

\section{Table 1. Interview questions}

Question 1 What technologies did/do you use to educate yourself on your or your baby's health?

Question 2 What technologies do you use to communicate with health providers?

Question 3 What did you like/not like about the technologies and how would you improve them?

\section{Data analysis}

The audio-recorded data were transcribed verbatim. The transcriptions were transferred to a coding sheet in Excel (14.7.1), where sentences were clustered to form codes and codes were clustered to form themes (Braun \& Clarke, 2006). An inductive thematic analysis was conducted by the authors (Māori and nonMāori researchers) to maintain the participant's mana (authority) and minimise the possibility of misinterpretation. This was achieved through continuous re-reading of the codes to identify, summarise and organise recurring themes, and for links between the research objectives and themes to be made (Braun \& Clarke, 2006; Thomas, 2006).

\section{FINDINGS}

There were nine participants in this study (Table 2), seven women and two men. The age range of the participants was 18 to 46 years. The gestation time for the pregnant women ranged from 29 to 35 weeks.

\section{Table 2. Participant demographics}

\begin{tabular}{llll} 
Pseudonym & Ethnicity* & Age & $\begin{array}{l}\text { Age of baby/weeks } \\
\text { pregnant }\end{array}$ \\
Hana & NZ European & 23 & 35 weeks pregnant \\
Aroha & Māori & 21 & 29 weeks pregnant \\
Larissa & $n s^{* *}$ & 23 & 33 weeks pregnant \\
Nico & Argentinian & 28 & Larissa's partner \\
Kamaia & Māori & 18 & 16 month old baby \\
Arehana & Māori & 18 & 33 weeks pregnant \\
Miranda & NZ European & 29 & 32 weeks pregnant \\
Thomas & NZ European & 29 & Miranda's partner \\
Atarangi & Māori & 46 & $\begin{array}{l}\text { Pregnant with 4th child, } \\
\text { weeks ns }\end{array}$ \\
\hline
\end{tabular}

${ }^{*}$ ethnicity was self-identified, ${ }^{* *}$ not specified

Four overarching themes emerged: information, communication, barriers, and facilitators, which are explained with their associated sub-themes. As there were no obvious differences between Māori and non-Māori narratives, all data were aggregated. Participants used technologies to access health-related information and to communicate with their healthcare providers during the perinatal period. Various barriers and facilitators influenced their ability to access this information or to communicate.

\section{Information}

Range of tools and rangatiratanga (self-governance)

A range of online tools and services was used to gain health-related information and these enabled autonomous decision-making by participants. Women texted or called their LMC and used smartphones and computers to access information through Google searches and webpages. Participants were members of private and public mothering groups on Facebook, used pregnancy mobile apps, called the Ministry of Health (2017) helpline "Healthline" and watched a Vlogger (video blogger). These resources and services supplemented books, breastfeeding workshops, routine antenatal care appointments and advice from family and friends. Participants used tools simultaneously to compare information or conduct "research", which exemplified rangatiratanga in autonomous decision-making. Hana and Aroha demonstrate using a range of tools.

Hana: Doctor Google.

Aroha: Yeah, Google and actually some mum pages on Facebook.

Hana: My one is the Ministry of Health, New Zealand website... Or my main one is that I'll ring Healthline, cos then they have the nurse and they run you through the symptoms.

Aroha: I've got a pregnancy app!

Hana: Yeah, I've got the same pregnancy app.

\section{Diversity of information}

Participants accessed a range of health-related information, including subjects such as physical health, mental wellbeing, nutrition and parenting. Participants appreciated the weekly updates on their pregnancy journey apps and on some websites, regarding changes occurring during the pregnancy, such as their baby's growth. Atarangi used the weekly updates to "remind" herself of what developmental stages she and her baby were experiencing:

.... and also about every week, what week stage you're at just to remind me.... it just has a week-by-week pregnancy update for what stage you're at, what stage your baby's at...

\section{Credibility and reputability}

Most participants were able to discern credible and reputable tools and acknowledged that incorrect information is often shared online. Participants defined credibility as the trustworthiness of the information, whereas reputability referred to the extent to which the source was recognised as an esteemed health-related organisation.

The Ministry of Health and its services were regarded as reputable and were believed to distribute credible information. Credibility was questioned when there was a lack of references provided, when information was out-dated or irrelevant to the New Zealand healthcare system, and in advice shared among Facebook group members. Aroha and Hana exemplified this by recalling that some women sought diagnoses on Facebook, rather than seeing a doctor.

Hana: There's always a lot of mums that are like, 'here's a picture of this rash... what is it?' And there's like 20 people that are like 'yeah, it's measles'.

Aroha: Like asking other mums, as if they're doctors!

Hana: It's like -just go to the doctor!' 


\section{Knowledge sharing}

Participantsvalued sharing advice and experience-based information with their families, partners or wider virtual communities, such as Facebook groups. The tuakana-teina relationship (older expert teaching the younger and less knowledgeable) was evident in Kamaia and Arehana. Both young women asked their older sister, their tuakana, who already had a baby of her own, for pregnancy advice. The information that was shared among other families, couples and wider networks related to abnormalities, pregnancy complications, skills, such as measuring the baby during pregnancy, and experiences with treatments. However, half of the participants were ambivalent toward receiving medical advice from complete strangers. Aroha and Hana stressed the difference between seeking medical diagnoses and seeking experience-related advice online:

\begin{abstract}
Hana: ...say things like your kid's got eczema and you know, this cream you've got isn't working, like 'What do you guys use?' And then people can be like, 'Oh, I had this great experience with this and this was terrible and like that kind of thing is really good.' But when it comes down to an actual medical diagnosis or something that people are actually relying on Facebook to diagnose, actual medical conditions and it's, like, 'noooo!'
\end{abstract}

Aroha: That's the difference, aye!

\section{Communication}

Seven participants reported using mainstream modes of communication to make in-person appointments or request advice from their LMC, namely through calling or texting on mobile and landline phones. One couple did not use any technologies, as appointments were pre-booked. Only Aroha reported using a patient portal for convenience, as her health provider was a 20 -minute drive from where she resided. A patient portal is a type of personal health record managed by the patient (Tang, Ash, Bates, Overhage, \& Sands, 2006). These often allow patients to view aspects of their medical records, book appointments, access health information, message their provider and request repeat prescriptions.

\section{Kanohi ki te kanohi (face-to-face)}

All participants valued the routine kanohi ki te kanohi communication with their LMCs, due to feeling connected and comfortable. Communicating in person was reported to be more familiar and easier than learning to use a new technology. Participants preferred in-person contact due to the natural flow of energy, which created a real, physical, nurturing and comfortable interaction.

\section{Larissa: I wouldn't like to have a [n] antenatal or midwife's appointment over the phone or online... the energy just doesn't flow as naturally... I guess when you're kind of in a room with someone you can kind of pick up on people's energies and.... You feel more comfortable as well when you're with someone in person and it is more of a nurturing environment.}

Nico: When you get to the room, you give them a hug first and then you start talking..

Larissa: Yeah, more personable interaction I guess, that's what I like a lot better than that.

\section{Barriers}

Barriers were related to the technologies or the experience of using them. Participants reported technology-related barriers such as complexity, lagging (slow responses by the device) and a need for up-to-date devices and data. Hana emphasised the complexity of setting up a patient portal system.

\section{I've just found it's a real pain in the ass to set it up, so I never really followed through with it! They gave me this huge pamphlet, you know, and I just can't be bothered with it!}

Obstacles pertinent to the experience of engaging with tools were related to whakamā (being shy/embarrassed) and privacy concerns. Aroha and Hana reported that whakamā was aggravated when talking on the phone as they primarily communicated by text messaging.

\section{Aroha: I get nervous talking to anybody on the phone! ... \\ Making appointments for anything, it's not my thing. I don't like doing it.}

Hana: It makes us sound like the most pathetic people... but actually, like everything you do now is just typing on your phone.

Nico and Larissa emphasised privacy concerns whereby they encountered personalised advertising on Google and Facebook that was based on previous searches done on the device. This was particularly alarming to Larissa who had not released pregnancyrelated information on Facebook but found expectant "mothersto-be" advertisements appearing on her Facebook when she used it:
I'll tell you something that sort of freaked me out... I am on Facebook but I'm not the type of person to announce on Facebook that I'm having a baby... so the Facebook world technically doesn't know that I'm having a baby, but um on my timeline it always comes up with ads promoting mother things, like expectant-mothers-to-be, and this never happened before. But it is now because I'm researching this stuff on my phone.

\section{Improvements}

Some recommendations from participants were made for what they perceived to be improvements for the technologies they used. Aroha and Hana suggested that being able to text LMCs, rather than only talking on the telephone, would improve accessibility as women may feel less whakamā. Kamaia reported being dependent on internet data to access perinatal health-related information online, thus suggested access to "more data". Lastly, Larissa suggested more use of visual content in video blogs (Vlogs):

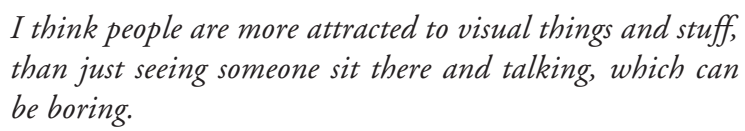

\section{Facilitators}

\section{Access}

Regarding the various technologies, participants liked the convenience, cost-effectiveness, ease-of-use, and the ability to obtain information instantly. Technologies, such as texting that allowed for quick access to LMCs, assisted communication and engagement with health services. Personal convenience and physical access were emphasised, as the ability to seek information online traversed geographical barriers and overcame the need to travel or wait for clinic opening hours. Participants also acknowledged that technologies allowed midwives to communicate when it was most convenient for them, as they often have busy schedules. Aroha reinforced how these aspects influence accessing health care:

I understand that a lot of mums probably don't have cars, don't travel, don't drive, which would make it harder, you 
know, if you've got more than one child, but that's where social media comes in.

\section{Emotional}

Emotional facilitators were explained through the promotion of hinengaro (mental wellbeing) and whakamana (confidence). This was evident by relief and confidence replacing worry, as the ability to quickly talk to a provider through technologies was reassuring. Participants called Healthline or texted their midwife about their concerns, especially during their first pregnancy as they knew they could gain an "end result" quickly. Reassurance was reported regardless of whether the situation was an emergency, and participants were generally informed that everything was fine, as Miranda explained:

Having my first baby, some of the pains or discomforts I'm feeling and I don't know if they're normal or abnormal, whether to worry about them or not, so I text questions through. Usually it's just a text back saying it's normal.

\section{DISCUSSION}

Technology use during the perinatal period by Kaupapa Māori health service users was explored in the context of Māori values and philosophies. The study identified a range of online tools and services that were being used to gain health-related information during the perinatal period. It also identified which technologies were being used to communicate with midwife LMCs and to book appointments. The tools and services were synergised with existing care and the knowledge of each user's midwife LMC, so were valued by participants.

As women increasingly gain internet access and use mobile devices, it is useful for midwives to be aware of the range of tools and services being used, and how they may be used to complement the care and information they provide. LMC midwives may be one of the few professional groups who use text messaging for contact and support, due to the demographic needs of their clients.

A Māori-centred approach was important in this study to identify barriers to healthcare and ensure that services are responsive to Māori (Reid et al., 2017). This was evident in the sub-themes of kanohi ki te kanohi and knowledge sharing amongst whānau, which are influential determinants of health for indigenous populations (Cram et al., 2003; Durie, 2006). Indigenous health scholars reinforce the importance of friendly interactions and the inclusion of cultural values such as kanohi ki te kanohi in promoting rapport and creating meaningful relationships and safe spaces for communication (Cram et al., 2003; Mead, 2003; van Herk, Smith, \& Tedford Gold, 2012). Participants highly valued the different connection they felt meeting with their LMC in person and reflected this by speaking about being able to "hug" their provider and the "natural flow of energy" that they felt when communicating personally. Encounters as such have been described as "high tech, high touch" or achieving the balance between humanness and technology (Ho, 2010). Finding a balance when employing technologies is important, to ensure that some processes in healthcare delivery are simplified whilst the relevance of in-person providers is not lost $(\mathrm{Ho}, 2010)$. Maternity care requires regular assessment of both maternal and neonatal health so will always require physical assessment through faceto-face appointments. This study has identified that information technologies can be used to supplement, but should not be used to replace, face-to-face appointments.

Conversely, appointments limited to a physical space may invite barriers as some healthcare professionals struggle to create respectful environments (Eggleton et al., 2017), although participants reported that their midwife was able to establish nurturing environments. Previous research shows that successful engagement with health professionals is jeopardised by poor communication, conflicting advice and provider behaviour that is insensitive to cultural differences (Glover et al., 2007; Makowharemahihi et al., 2014). This can result in women distrusting health professionals and create barriers to engagement with healthcare professionals and the support and care they provide (Glover et al., 2007).

Identifying issues such as lagging and complexity as barriers to using technologies was consistent with previous research by Rojjanasrirat, Nelson and Wambach (2012) and Seguranyes et al. (2014). However, other findings were novel. The concept of whakamā, is rarely applied to telehealth. Younger participants described feeling anxious about talking on the phone and felt more confident texting or messaging their midwife LMC. Eggleton et al. (2017) also identified aversion to talking on the phone as a barrier to accessing healthcare and discussed how visual methodologies may offer less chance of misunderstanding compared to oral communication. This finding provides insight into the popularity of text use amongst younger generations and the changing culture of telephone use.

Challenges are also associated with texting for midwives, including delayed transmission of messages due to loss of connection, security breaches and exposure to private medical information by someone unauthorised who reads the messages, misinterpretation and less depth of the information being relayed, compared to phone calls (Midwifery Council of New Zealand [MCNZ], 2016). The Midwifery Council offers guidance on safely incorporating text messaging services into standard care, suggesting that women call in emergencies, that midwives communicate in normal English, rather than "text-speak" to avoid miscommunication, ensure that mobile devices are password-protected and do not perform clinical assessments via text (MCNZ, 2016). Regardless, the Midwifery Council emphasises that midwives should not avoid text messaging, as many households do not use landlines and it is easier to connect with women in hard-to-reach communities and can improve relationships and care through the ability to send supportive texts and promptly communicate reassuring test results. Consequently, despite some challenges for the midwifery profession, texting may increase women's confidence in navigating the health system due to greater opportunities to exchange questions and answers, clarify understanding, and receive reassurance.

Unexpectedly, participants did not comment on the affordability of technologies. This may suggest that participants were already connected to the internet or were a relatively privileged cohort. Given that Northland is a fairly deprived area and Māori, as with many other indigenous peoples, experience greater levels of deprivation than their non-indigenous counterparts, affordability could be considered for future interventions and research (National Health Committee, 2010).

Facilitators for telehealth use during the perinatal period, such as convenience, cost, ease-of-use, instant information, reassurance and confidence were also consistent with previous studies (Entsieh et al., 2015; Friesen et al., 2015; Gund et al., 2013; Hod \& Kerner, 2003; Jareethum et al., 2008; Lindberg et al., 2009). Our study revealed that technology might benefit providers too, as participants assumed that communicating through technologies was more convenient for their midwife. Prolonged interactions can be explained through an asynchronous communication model, whereby information exchange is not actively simultaneous, such as email rather than talking on the phone (Venes, Fenton, \& Patwell, 2017). This form of communication is becoming more popular within the health sector, due to an increased use of telehealth, patient demand and preference, a changing health market and 
easily facilitated consultations (Wilson, 2003). Advantages of asynchronous communication in health systems tend to focus on user benefit, thus it was interesting that participants also considered their midwife's convenience. This finding suggests that users may be aware of their provider's workload, therefore addressing the fear of many providers regarding increased workload due to more easily accessible communication (Bardsley, Steventon, \& Doll, 2013; Taylor, Coates, Wessels, Mountain, \& Hawley, 2015). This reinforces the need both for perinatal health providers to up-skill and embrace information technologies and for the inclusion of both providers and service users in future research on telehealth use.

Participants had selected their own electronic information resources and appeared to be satisfied with the quality of their selection. Most were able to discern credible and reputable tools but acknowledged that incorrect information is often shared online, especially in Facebook groups. This raises the question of midwife LMCs being able to support their clients' selection and use of these technologies. Technologies emerge, change and disappear rapidly, making it challenging to keep up to date with relevant apps, websites, Vlogs and other services. It is possible for midwife LMCs to assist their clients in selecting resources by using the Mobile App Rating Scale created by Stoyanov et al. (2015) or inviting staff at healthnavigator.org.nz to rate selected apps, or to check that websites are approved by Health on the Net Foundation (2018). While it is useful for midwife LMCs to prescribe apps and websites, it is not necessary to do so. Knowing how to identify apps and websites selected by their clients as trustworthy and of high quality may be more useful than prescribing.

\section{STRENGTHS AND LIMITATIONS}

This study provided Māori and non-Māori perspectives to telehealth, illustrating that health services should be responsive to Māori. It helped to inform the participating DHB on a group of their service users' engagement with telehealth and can be used to improve perinatal services and contribute towards interventions to reduce inequities in maternal and infant mortality.

As an exploratory study with a small sample size of nine participants that was limited to Northland, findings are neither entirely transferable nor generalisable. Despite this, the study centralised Māori values and was conducted collaboratively so that it is meaningful to Māori (Smith, 1992). This study may encourage more non-Māori researchers to apply Kaupapa Māori consistent research in partnership with Māori.

\section{CONCLUSION}

The study has demonstrated that information technologies play an important role in minimising barriers to perinatal healthcare by facilitating the distribution of health-related information and promoting provider engagement. It also identified barriers and facilitators that prevented or enabled engagement with these technologies and, ultimately, access to information and effective communication. The findings suggest that the available online tools and services are generally adequate, from the standpoint of our sample, and that Māori health values such as whānau and kanohi ki te kanohi are important for successful perinatal healthcare delivery via telehealth. More research is needed to explore how widely technologies influence pregnant women and their health care.

\section{ACKNOWLEDGEMENTS AND CONFLICT OF INTEREST DISCLOSURE}

The authors would like to thank their participants, and the Tōmaiora Māori Health Research Group, Kathrine Clarke, the NDHB Maternal and Child Health Service managers, the kaimahi and the Ngāti Hine Health Trust for their involvement, support and guidance during this research. We also thank The School of Population Health and Te Kupenga Hauora Māori, The University of Auckland, for their financial assistance towards the research.

The authors declare that there are no conflicts of interest.

\section{Key messages}

- There are often barriers for Māori and rural populations to accessing care during or following pregnancy. Technology can help reduce these barriers by making health information more accessible.

- Researchers explored the use of technology with nine participants using Kaupapa Māori methodology.

- Health technology is effective and responsive to Māori; however, values such as whānau (extended family structures) and kanohi ki te kanohi (face-to-face interactions) need to be incorporated and respected.

\section{REFERENCES}

Bardsley, M., Steventon, A., \& Doll, H. (2013). Impact of telehealth on general practice contacts: findings from the whole systems demonstrator cluster randomised trial. BMC Health Services Research, 13(1), 395-403. Braun, V., \& Clarke, V. (2006). Using thematic analysis in psychology. Qualitative Research in Psychology, 3(2), 77-101.

Corbett, S., Chelimo, C., \& Okesene-Gafa, K. (2014). Barriers to early initiation of antenatal care in a multi-ethnic sample in South Auckland, New Zealand. New Zealand Medical Journal, 127(1404), 53-61.

Cram, F., Smith, L., \& Johnstone, W. (2003). Mapping the themes of Māori talk about health. New Zealand Medical Journal, 116(1170), 1-7. Durie, M. (2006). Measuring Māori wellbeing. Paper presented at the New Zealand Treasury Guest Lecture Series, Wellington.

Eggleton, K., Kearns, R., \& Neuwelt, P. (2017). Being patient, being vulnerable: exploring experiences of general practice waiting rooms through elicited drawings. Social \& Cultural Geography, 18(7), 971-993. Entsieh, A.A., Emmelin, M., \& Pettersson, K. (2015). Learning the $\mathrm{ABCs}$ of pregnancy and newborn care through mobile technology. Global Health Action, 8(1), 1-10.

Friesen, C., Hormuth, L., Petersen, D., \& Babbitt, T. (2015). Using videoconferencing technology to provide breastfeeding support to lowincome women: Connecting hospital-based lactation consultants with clients receiving care at a community health center. Journal of Human Lactation, 31(4), 595-599.

Glover, M., Manaena-Biddle, H., \& Waldon, J. (2007). Influences that affect Maori women breastfeeding. Breastfeeding Review, 15(2), 5-14.

Glover, M., Waldon, J., Manaena-Biddle, H., Holdaway, M., \& Cunningham, C. (2009). Barriers to best outcomes in breastfeeding for Māori: Mothers' perceptions, whānau perceptions, and services. Journal of Human Lactation, 25(3), 307-316.

Gund, A., Sjöqvist, B., Wigert, H., Hentz, E., Lindecrantz, K., \& Bry, K. (2013). A randomized controlled study about the use of eHealth in the home health care of premature infants. BMC Medical Informatics and Decision Making, 13(1), 22-33.

Health on the Net Foundation. (2018). Retrieved from https://www. hon.ch/en/about.html 
Ho, J. (2010). Consumer Health Informatics. In E. Hovenga, M. Kidd S. Garde, \& C. Cossio (Eds.), Health Informatics: An overview (pp. 185194). IOS Press Ebooks.

Hod, M., \& Kerner, R. (2003). Telemedicine for antenatal surveillance of high-risk pregnancies with ambulatory and home fetal heart rate monitoring - an update. Journal of Perinatal Medicine, 31(3), 195-200.

Jareethum, R., Titapant, V., Chantra, T., Sommai, V., Chuenwattana, P., \& Jirawan, C. (2008). Satisfaction of healthy pregnant women receiving short message service via mobile phone for prenatal support: A randomized controlled trial. Journal of the Medical Association of Thailand, 91(4), 458-463.

Jones, R. (2000). Traditional Maori Healing. Pacific Health Dialog, 7(1), 107.

Jones, R., Crengle, S., \& McCreanor, T. (2006). How Tikanga guides and protects the research process: Insights from the Hauora Tāne Project. Social Policy Journal of New Zealand, 29, 60-77.

Lindberg, B., Axelsson, K., \& Öhrling, K. (2009). Taking care of their baby at home but with nursing staff as support: The use of videoconferencing in providing neonatal support to parents of preterm infants. Journal of Neonatal Nursing, 15(2), 47-55.

Lund, S., Nielsen, B., Hemed, M., Boas, I., Said, A., Said, K., . . . Rasch, V. (2014). Mobile phones improve antenatal care attendance in Zanzibar: a cluster randomized controlled trial. BMC Pregnancy and Childbirth, 14(29), 1-10.

Makowharemahihi, C., Lawton, B., Cram, F., Ngata, T., Brown, S., \& Robson, B. (2014). Initiation of maternity care for young Māori women under 20 years of age. New Zealand Medical Journal, 127(1393), 52-62.

Malpas, P., Anderson, A., Wade, J., Wharemate, R., Paul, D., Jacobs, P., ... Lunistra, D. (2017). A critical exploration of a collaborative Kaupapa Māori consistent research project on physician-assisted dying. New Zealand Medical Journal, 130(1454), 47-54.

Mane, J. (2009). Kaupapa Māori: A community approach. MAI Review, 3(1), 1-9.

Mead, H. (2003). Tikanga Māori: Living by Māori Values. Wellington: Huia Publishers.

Midwifery Council of New Zealand. (2016). Be Safe. 02. Text Messaging. Retrieved from https://www.midwiferycouncil.health.nz/ sites/default/files/images/Be\%20Safe\%202\%20Text\%20Messaging.pdf

Ministry of Health. (2015). Maternity Consumer Survey 2014.

Retrieved from https://www.health.govt.nz/system/files/documents/ publications/maternity-consumer-survey-2014-sep15.pdf

Ministry of Health. (2017). Healthline. Retrieved from http://www. health.govt.nz/your-health/services-and-support/health-care-services/ healthline

National Health Committee. (2010). Rural Health: Challenges of Distance, Opportunities for Innovation. Wellington: National Health Committee.

Perinatal and Maternal Mortality Review Committee. (2017). Eleventh annual report of the perinatal and maternal mortality review committee: Reporting mortality 2015. Retrieved from: https:/www.hqsc.govt.nz/assets/ PMMRC/Publications/2017_PMMRC_Eleventh_Annual_Report.pdf Pipi, K., Cram, F., Hawke, R., Hawke, S., Huriwai, T., Mataki, T., . .. Tuuta, C. (2004). A Research Ethic For Studying Maori And Iwi Provider Success. Social Policy Journal of New Zealand, 23, 141-153. Reid, P., Paine, S., Curtis, E., Jones, R., Anderson, A., Willing, E., \& Harwood, M. (2017). Achieving health equity in Aotearoa: strengthening responsiveness to Māori in health research. New Zealand Medical Journal, 130(1465), 96-103.

Reid, P., \& Robson, B. (2007). Chapter 1: Understanding health inequities. In B. Robson \& R. Harris (Eds.), Hauora: Māori standards of health IV-A study of the years 2000-2005. (pp. 3-10). Wellington: Te Rōpū Rangahau Hauora a Eru Pōmare.

Research New Zealand. (2015). A Report on a Survey of New Zealanders' Use of Smartphones and other Mobile Communication Devices 2015. Wellington: Research New Zealand.

Rojjanasrirat, W., Nelson, E., \& Wambach, K. (2012). A pilot study of home-based videoconferencing for breastfeeding support. Journal of Human Lactation, 28(4), 464-467.

Seguranyes, G., Costa, D., Fuentelsaz-Gallego, C., Beneit, J.,

Carabantes, D., Gómez-Moreno, C., . . Group, P.T.R. (2014). Efficacy of a videoconferencing intervention compared with standard postnatal care at primary care health centres in Catalonia. Midwifery, 30(6), 764771 .

Smith, G. (1992). Research Issues Related to Māori Education. In The Issue of Research and Māori. Auckland: Research Unit for Māori Education, The University of Auckland.

Statistics New Zealand. (2013). Census of Population and Dwellings. Retrieved from http://www.stats.govt.nz/Census.aspx

Stoyanov, S., Hides, L., Kavanagh, D., Zelenko, O., Tjondronegoro, D., \& Mani, M. (2015). Mobile app rating scale: A new tool for assessing the quality of health mobile apps. Journal of Medical Internet Research, 3(1), e27.

Tang, P., Ash, J., Bates, D., Overhage, J., \& Sands, D. (2006). Personal health records: Definitions, benefits, and strategies for overcoming barriers to adoption. Journal of the American Medical Informatics Association, 13(2), 121-126.

Taylor, J., Coates, E., Wessels, B., Mountain, G., \& Hawley, M. (2015). Implementing solutions to improve and expand telehealth adoption: participatory action research in four community healthcare settings. BMC Health Services Research, 15(1), 529-540.

Te Rōpū Rangahau Hauora a Eru Pōmare. (2015). Mana Whakamārama - Equal Explanatory Power: Mãori and non-Māori sample size in national health surveys. Retrieved from: https://www.fmhs.auckland.ac.nz/assets/ fmhs/faculty/.../Equal_explanatory_power.doc

Thomas, D. (2006). A General Inductive Approach for Analyzing Qualitative Evaluation Data. American Journal of Evaluation, 27(2), 237-246.

Tōmaiora. (2015). Tōmaiora Māori Health Research Group Guidelines. Retrieved from: https://www.fmhs.auckland.ac.nz/assets/fmhs/faculty/ tomaiora/docs/T\%C5\%8Dmaiora manual 2015.pdf

Van Herk, K., Smith, D., \& Tedford Gold, S. (2012). Safe care spaces and places: Exploring urban aboriginal families' access to preventive care. Health \& Place, 18(3), 649-656.

Venes, D., Fenton, B., \& Patwell, J. (2017). Taber's Cyclopedic Medical Dictionary (23rd ed.). Philadelphia: F.A. Davis Company.

Wilson, E. (2003). Asynchronous health care communication. Communications of the ACM, 46(6), 79-84.

Wootton, R., \& Bonnardot, L. (2015). Telemedicine in Low-Resource Settings. Frontiers in Public Health, 3(3), 1-3.

World Health Organization. (2017). Maternal and perinatal health. Retrieved from http://www.who.int/maternal_child_adolescent/topics/ maternal/maternal_perinatal/en

\section{Accepted for Publication February 2019}

Gasteiger, N., Anderson, A., \& Day, K. (2019) Rethinking engagement: Exploring women's technology use during the perinatal period through a Kaupapa Māori consistent approach. New Zealand College of Midwives Journal, 55, 20-26.

https://doi.org/10.12784/nzcomjnl55.2019.3.20-26 